\title{
Statistical investigation of reservoir-induced seismicity in Aswan area, Egypt
}

\author{
Mahmoud Mohamed Selim ${ }^{1 *}$, Masajiro Imoto ${ }^{2}$, and Nobuo Hurukawa ${ }^{1}$ \\ ${ }^{1}$ International Institute of Seismology and Earthquake Engineering, Building Research Institute, Tsukuba 305-0802, Japan \\ ${ }^{2}$ National Research Institute for Earth Science and Disaster Prevention, Tsukuba 305-0006, Japan
}

(Received September 18, 2000; Revised December 3, 2001; Accepted January 14, 2002)

\begin{abstract}
The purpose of this study is to understand the effect of the fluctuation of the water level in Lake Nasser on the seismicity in the Aswan area, Egypt. Two statistical methods have been applied using the sequence of seismic events between 1982-1998 with local magnitude $m \geq 2.0$, recorded by the Aswan Regional Seismological Center in Egypt. Firstly, a cross-correlation method is adopted to find the relationship between the water level and the seismicity. A maximum correlation coefficient of +0.55 was obtained for the period (1982-1985) at a 60 days time lag. However, coefficients are very small for other periods. Secondly, a point-process procedure is applied to the seismicity for the period (1992-1998), where a hazard function includes a term presenting reservoir-induced seismicity. This analysis confirms a weak relation between the fluctuation of the water level and the seismicity in the area. The result suggests that the seismicity in the area becomes active during a period when the water level is decreasing from the maximum to the minimum.
\end{abstract}

\section{Introduction}

There has been increasing interest over the past two decades in the occurrence of reservoir-induced seismicities. Experimental results were obtained for Nurek reservoir (Simpson and Negmatullaev, 1981; Keith et al., 1982), Lake Mead (Anderson and Laney, 1975; Rogers and Lee, 1976), Lake Kariba (Gough and Gough, 1976; Snow, 1972), Lake Oroville (Bell and Nur, 1978), Tarbela reservoir (Ibenbrahim et al., 1989), Xinfengjiang and Danjiangkou reservoirs (Chen and Talwani, 1998) and Fierza and Komani reservoirs (Muco, 1998). In some cases the direct correlation pronounced increases in seismicity with the first filling of the reservoir makes the casual relationship obvious. However, there are many cases in which there remains doubt as to whether the reservoir was directly responsible for the increased seismicity. The most conclusive cases for the induced seismicity are those relatively rare instances where there are data available from detailed monitoring of the reservoir region prior to impounding and where there is a substantial increase in seismicity on the first filling of the reservoir (e.g., Nurek reservoir; Simpson and Negmatullaev, 1981). Even in the absence of detailed monitoring using sensitive instruments, the onset of felt earthquakes with the initial impounding is sometimes sufficient to establish a correlation between the filling and the seismicity (Hoover, Koyna, Kariba, Hsinfengkiang). In other cases (e.g. Oroville, Lake Nasser) there may be considerable delay between the initial filling and the start of the detectable seismicity (Simpson et al., 1988).

*Present address: Aswan Seismological Data Center, National Research Institute of Astronomy and Geophysics, Aswan, Egypt.

Copy right (C) The Society of Geomagnetism and Earth, Planetary and Space Sciences (SGEPSS); The Seismological Society of Japan; The Volcanological Society of Japan; The Geodetic Society of Japan; The Japanese Society for Planetary Sciences.
On November 14, 1981, an earthquake with magnitude 5.2 occurred in the Kalabsha area (Kebeasy et al., 1987), which lies in the western side of the reservoir (Lake Nasser) at a distance of about $60 \mathrm{~km}$ south of Aswan High Dam in Egypt. This earthquake occurred in depth of $25 \mathrm{~km}$ on the east-west Kalabsha fault beneath Gebel Marawa (Fig. 1), which was determined by using the WWSSN station at Helwan (HLW, $690 \mathrm{~km}$ north from the epicenter area) and also by using the National Earthquake Information Center (NEIC) of the U. S. Geological Survey. Some studies on characteristics of the seismic activity in surrounding areas of the Lake Nasser reservoir have already been carried out and published (Kebeasy et al., 1987, 1991; Simpson et al., 1989; Gaber, 1986; Sameh, 1992). For example, by dividing the analytical periods into two of decreasing and increasing of the water level, Sameh (1992) has found that the $b$ value was larger in the increasing periods than the decreasing periods of the water level. This result confirms that the $b$ value of reservoir-associated earthquakes is relatively higher than normally found for normal earthquakes (Gupta and Rastogi, 1976; Muco, 1998).

In this paper we study the relation between fluctuations of the water level in the Lake Nasser reservoir and the seismic activity in the area using two statistical methods in detail.

\section{Lake Nasser}

The Aswan High Dam on the River Nile in southern Egypt began construction on 1960 and completed on 1972 to develop industries using generated electric power and to stabilize water for irrigation. The dam created Lake Nasser, one of the largest reservoirs in the world, at the south of Aswan. The reservoir covers the area between Lat. $21^{\circ} 30^{\prime} \mathrm{N}$ and $24^{\circ} 00^{\prime} \mathrm{N}$, Long. $31^{\circ} 20^{\prime} \mathrm{E}$ and $33^{\circ} 30^{\prime} \mathrm{E}$ (Fig. 1), and extends over about $300 \mathrm{~km}$ in the Egyptian territory and about $180 \mathrm{~km}$ into Sudan attaining a width of about $6 \mathrm{~km}$. It has 


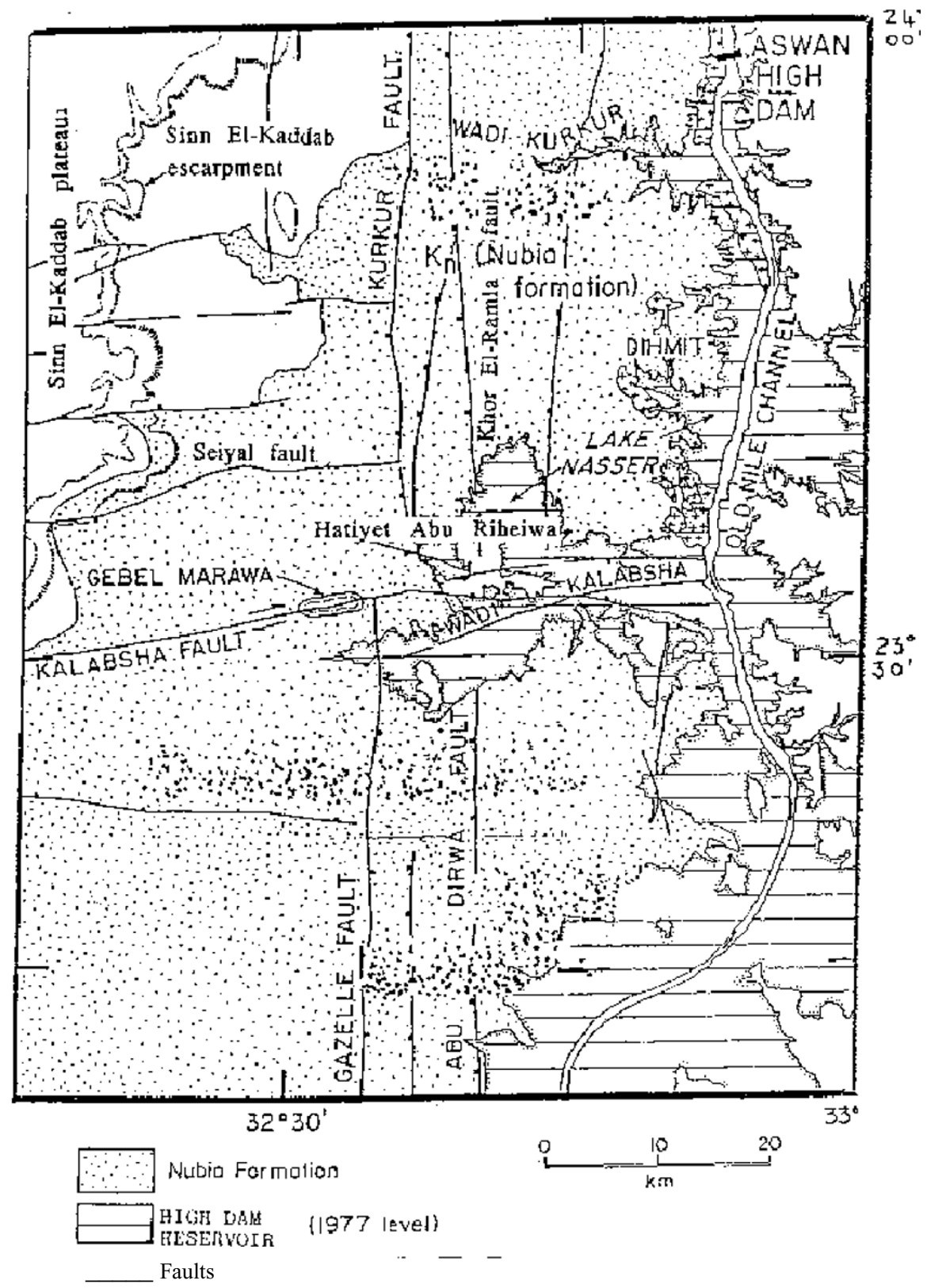

Fig. 1. Map of the western side of the Aswan High Dam reservoir (Kalabsha area). The dots, straight lines and the curve lines indicate the Nubia formation, the reservoir area and faults, respectively (after Issawi, 1978).

a capacity of approximately $162 \times 10^{9} \mathrm{~m}^{3}$, of which about $130 \times 10^{9} \mathrm{~m}^{3}$ is effectively considered for live storage. The maximum water depth in the dam site area is about $111 \mathrm{~m}$. The reservoir was first filled in 1964 and reached a water level of about $177.47 \mathrm{~m}$ above the mean sea level on November 1978, which corresponds to an average depth of $50 \mathrm{~m}$.

The earthquake of November 14, 1981 ( $m$ 5.2) and its aftershocks occurred along the Kalabsha fault, which extends from Wadi Kalabsha to Sinn El-Kaddab escarpment (Fig. 1), passing through Gebel Marawa and it appears to split on the eastern side of Gebel Marawa forming a number of parallel traces also in east-west direction. The fault lies down on 45 $\mathrm{km}$ south of the Aswan High Dam area. We have recognized that there are no records of earthquakes in all the reservoir area for the period 1964-1980 (Simpson et al., 1988). How- ever, after the reservoir's water level reached above $170 \mathrm{~m}$, felt earthquakes occurred in the Aswan area. Therefore, the recent seismic activity around the reservoir is a case of the induced seismicity.

\section{Data Acquisition}

When the November 14, 1981 earthquake ( $m$ 5.2) occurred, there was no local operating system of seismic stations. Using data of the NEIC from 1964 to 1974, we have recognized that there are no records of earthquakes in all the area around Aswan High Dam (Sameh, 1992). After the 1981 earthquake, the Aswan Regional Seismological Center network stations (13 stations) were installed by the cooperation between the National Research Institute of Astronomy and Geophysics (NRIAG) and High Dam Authority in col- 


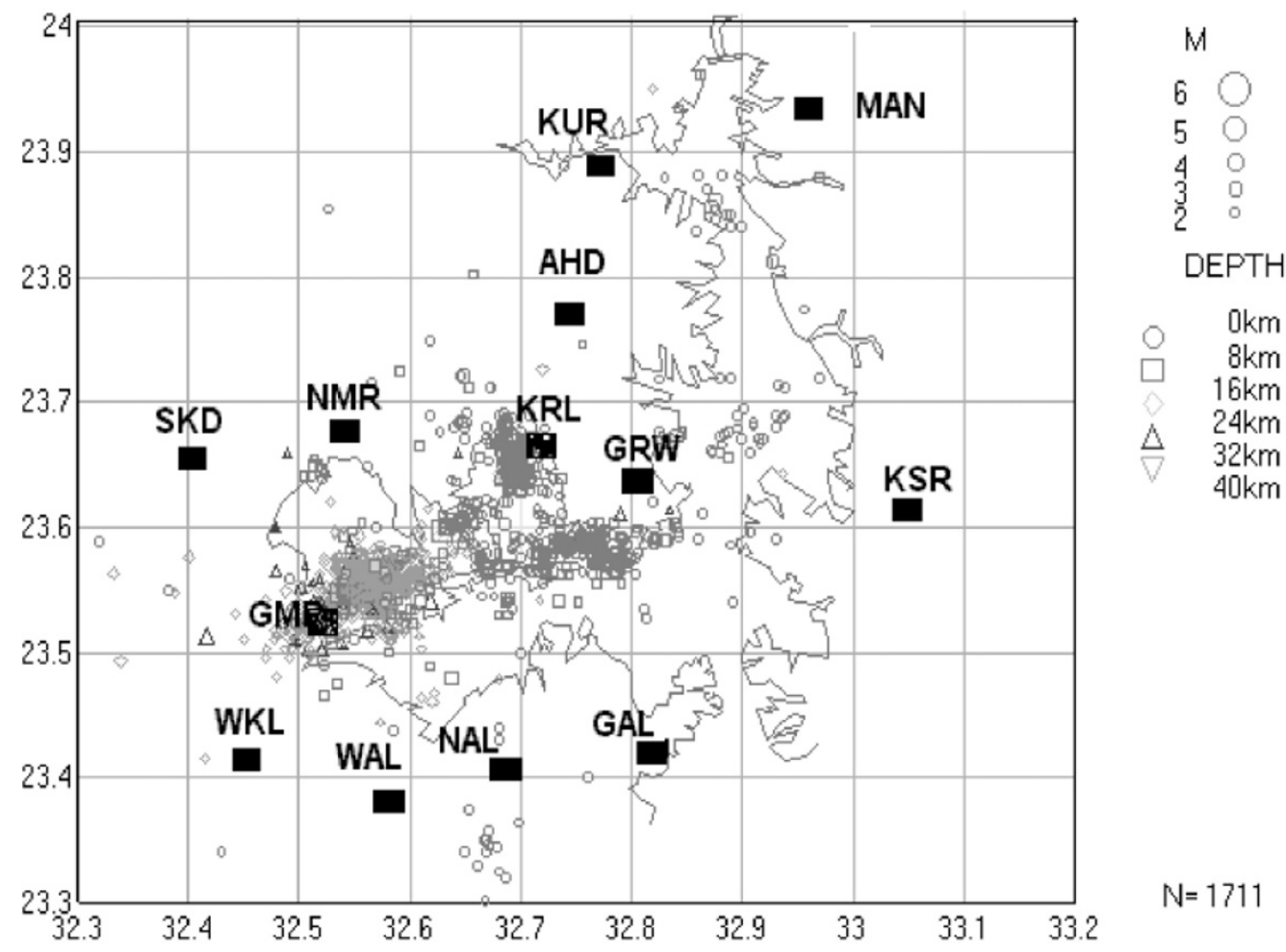

Fig. 2. The seismicity of the northern part of Lake Nasser determined by the Aswan Regional Seismological Center network $(m \geq 2.0)$ for the period 1982-1998. Sold squares represent seismic stations.

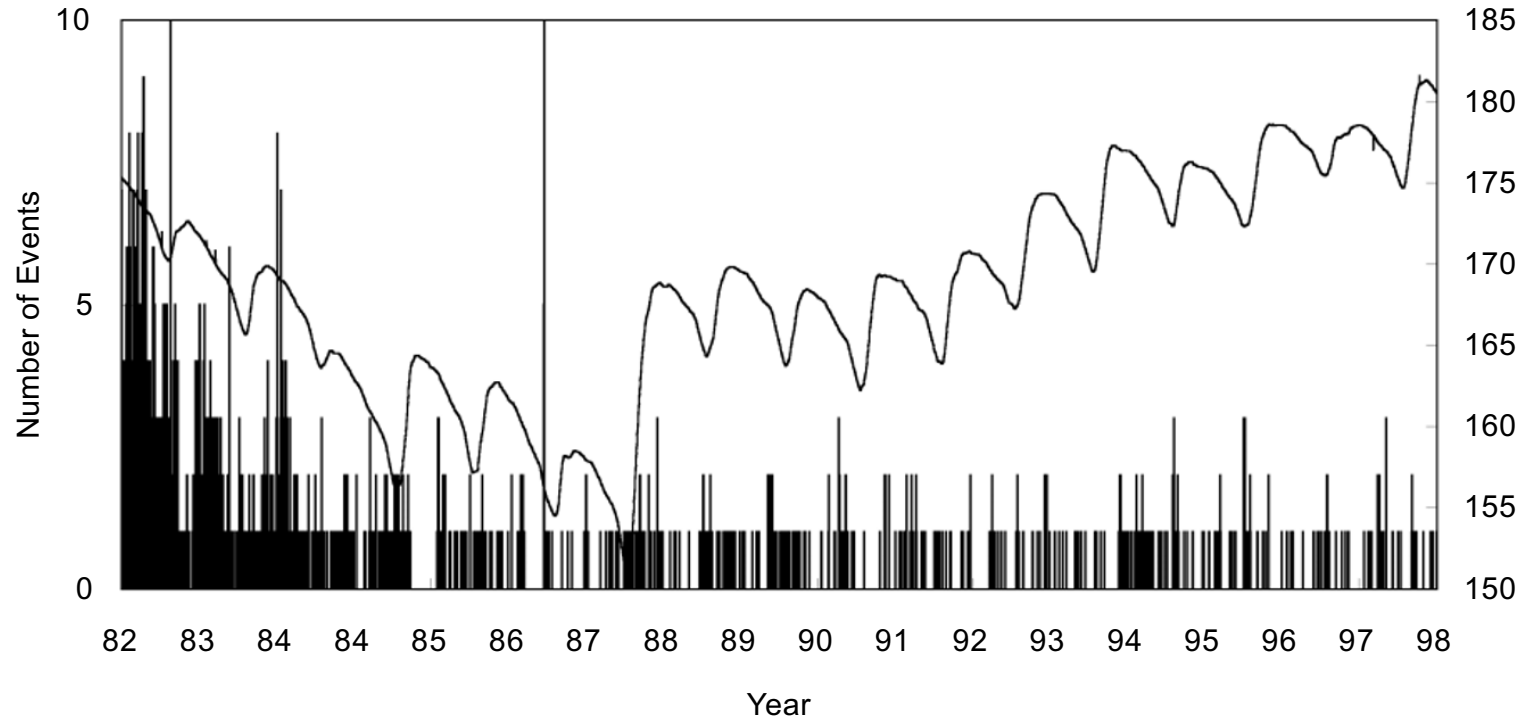

Fig. 3. Reservoir level of Lake Nasser and numbers of earthquakes ( $m \geq 2.0)$ per day that occurred in the area shown in Fig. 2 from 1982 to 1998 .

laboration with scientists from the Lamont-Doherty Geological Observatory of Columbia University (Fig. 2). Seventeen years of seismic monitoring in southern part of Egypt have revealed interesting seismic phenomena related to the filling of the reservoir of Lake Nasser. The observations have shown that the number of microearthquakes has increased after the impoundment and that many swarms have occurred in the vicinity of the reservoir (Fig. 2).
To understand the effect of the fluctuation of the water level in Lake Nasser on the seismicity in the Aswan area, the sequence of seismic events between 1982 and 1998 with $m \geq 2.0$ recorded by the network and the water level fluctuation data in the reservoir per day measured by Aswan High Dam Authority have been used (Fig. 3). The seismicity data used in this study consist of hypocenters that were determined using HYPO71 (Lee and Lahr, 1975) from $P$-wave 


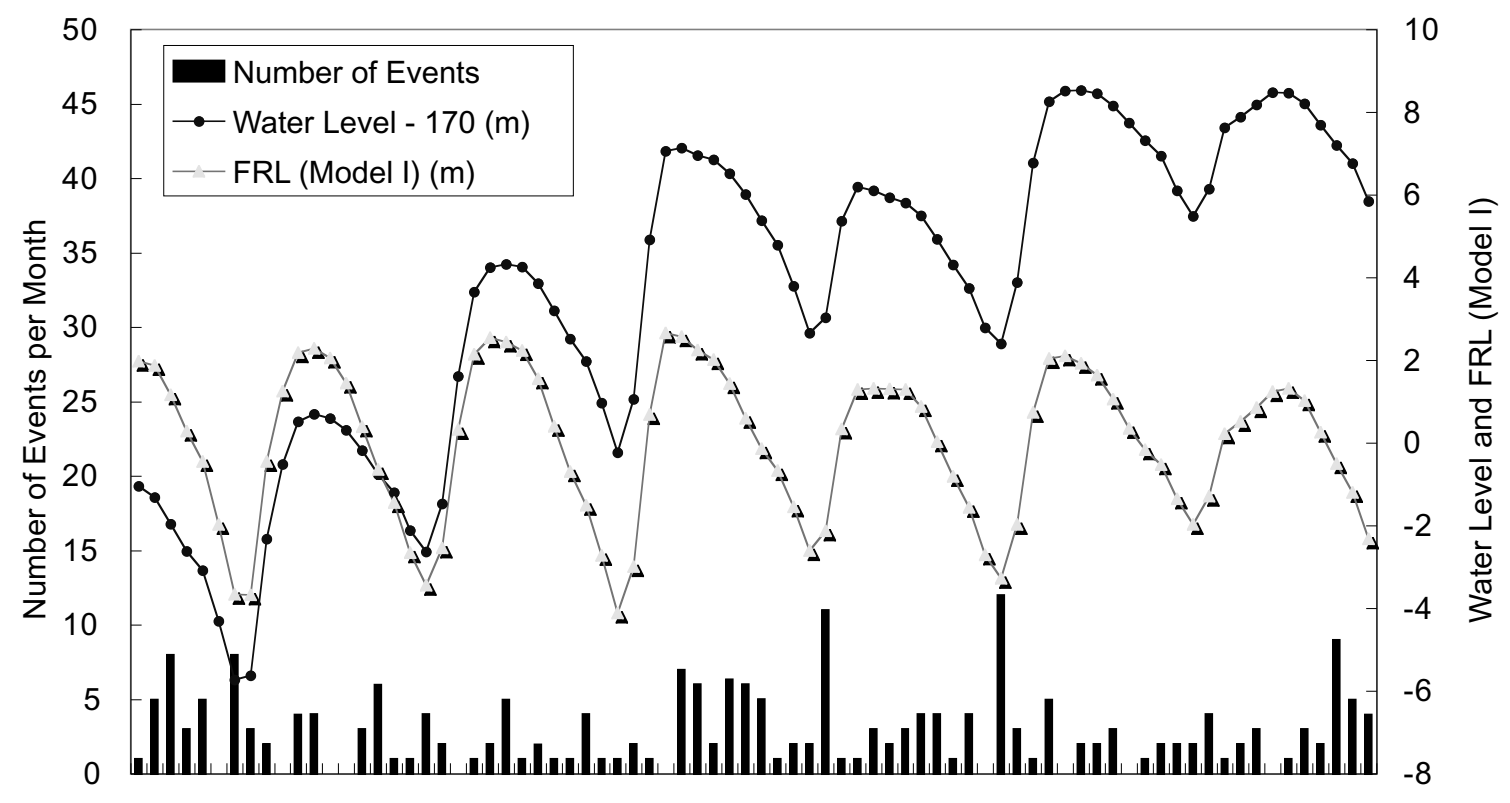

\begin{tabular}{|c|c|c|c|c|c|}
\hline ๙ั & ఝ̆ & চా & นึ & ๑ே & ڤ̆ \\
\hline 5 & 5 & 5 & 5 & 5 & $\overleftarrow{0}$ \\
\hline 5 & 5 & 5 & 5 & 5 & 5 \\
\hline
\end{tabular}

Fig. 4. Relationship between numbers of monthly events, monthly average of water levels and FRL for model I during the period $1992-1998$ in the area shown in Fig. 2 with depth range $(0-40 \mathrm{~km})$. Note that for the water level of $170 \mathrm{~m}$ deduction.

arrival times that were recorded by the network.

\section{Cross-Correlation Method}

To check the hypothesis that the fluctuations of the water level in the reservoir could influence the trend of the seismic activity (Gupta and Rastogi, 1976), the cross-correlation method has been carried out. A correlation coefficient provides a normalized measure and it is the measure of the linear relationship between two variables $X$ and $Y$. The correlation coefficient of random variables $X$ and $Y$ is defined by

$$
\operatorname{Corr}(X, Y)=\operatorname{Cov}(X, Y) / d x d y
$$

where $\operatorname{Cov}(X, Y)$ is the covariance of variables $X$ and $Y$, and $d x$ and $d y$ are the square roots of variances of variables $X$ and $Y$. In our analysis two variables $X$ and $Y$ represent the fluctuation of the reservoir's water level and the number of earthquakes, respectively, of which details are explained below.

For one series, monthly average values were calculated from daily observation of the reservoir's water level, and deviations of these values from moving average of a 13months window were adopted as the fluctuation data of the water level. For the other, average numbers of events per day were calculated at every month, and the monthly fluctuation of the number of events were obtained in the same way as that of the water level.

Computations were carried out for different periods (1982-1985, 1986-1991, 1992-1998, and 1982-1998), depths $(0-15 \mathrm{~km}, 15-40 \mathrm{~km}$, and $0-40 \mathrm{~km})$, and locations (long. $32.3^{\circ}-32.6^{\circ}, 32.6^{\circ}-33.2^{\circ}$, and $32.3^{\circ}-33.2^{\circ}$ ). Time delays of the earthquakes series to the reservoir series were considered in a range from 0 to 360 days at a 30 days step.
Figure 4 shows numbers of monthly events and monthly average of water levels during the period 1992-1998 with depth range $(0-40 \mathrm{~km})$ and location (long. $\left.32.3^{\circ}-33.2^{\circ}\right)$ as an example, since the data in this period is used in the next analysis, too.

Results obtained from this analysis were shown in Table 1 and plotted in Fig. 5. The best relationship between the water level in Lake Nasser and the earthquake number around it could be obtained for the period (1982-1985) at a 60 days time lag. The correlation coefficient is found to be +0.55 . Separating the data set into two subsets at the depth of 15 $\mathrm{km}$, similar values to this are obtained for the both subsets (Table 1). As is not shown here, shifting the time of start of the data range, mostly similar correlation charts to Fig. 5 for the same period of 1982-1985 are observed. These suggest that a maximum value of around 0.5 is stably attained as the correlation coefficient at this time range. However, coefficients are very low in other cases. For example, for the period (1992-1998) in the same hypocentral area as the previous case, it is found to be +0.16 at the same time lag (Table 1 and Fig. 5).

\section{Point-Process Modeling}

We considered an intensity function $\lambda$ consisting of three components, $\lambda_{o}, \lambda_{r}$, and $\lambda_{a}$, defined as,

$$
\lambda=\lambda_{o}+\lambda_{r}+\lambda_{a}
$$

where $\lambda_{o}, \lambda_{r}$, and $\lambda_{a}$ correspond to natural seismicity, reservoir-induced seismicity (RIS) and aftershock activities, respectively. We assumed that the natural seismicity is modeled by a stationary Poisson process with the constant intensity, $\lambda_{o}$. It is assumed that the RIS is related to the water 
Table 1. Correlation coefficients for cross-correlation method.

\begin{tabular}{cccccccc}
\hline \multirow{2}{*}{ Period } & & & & \multicolumn{4}{c}{ Correlation coefficient } \\
\cline { 5 - 7 } & Depth & Lat. & Long. & High & $\begin{array}{c}\text { Delay } \\
\text { (days) }\end{array}$ & Low & $\begin{array}{c}\text { Delay } \\
\text { (days) }\end{array}$ \\
\hline $1982-1985$ & $0-40$ & $23.3-24.0$ & $32.3-33.2$ & 0.55 & 60 & -0.63 & 180 \\
$1982-1985$ & $0-15$ & $23.3-24.0$ & $32.3-33.2$ & 0.54 & 60 & -0.51 & 180 \\
$1982-1985$ & $15-40$ & $23.3-24.0$ & $32.3-33.2$ & 0.42 & 60 & -0.56 & 180 \\
$1986-1991$ & $0-40$ & $23.3-24.0$ & $32.3-33.2$ & 0.08 & 360 & -0.08 & 180 \\
$1992-1998$ & $0-40$ & $23.3-24.0$ & $32.3-33.2$ & 0.16 & 60 & -0.18 & 0 \\
$1982-1998$ & $0-40$ & $23.3-24.0$ & $32.3-33.2$ & 0.20 & 60 & -0.19 & 210 \\
$1982-1998$ & $0-40$ & $23.3-24.0$ & $32.3-32.6$ & 0.13 & 90 & -0.11 & 210 \\
$1982-1998$ & $0-40$ & $23.3-24.0$ & $32.6-33.2$ & 0.11 & 90 & -0.11 & 300 \\
$1982-1998$ & $0-15$ & $23.3-24.0$ & $32.3-33.2$ & 0.11 & 90 & -0.10 & 330 \\
$1982-1998$ & $15-40$ & $23.3-24.0$ & $32.3-33.2$ & 0.09 & 360 & -0.07 & 120 \\
\hline
\end{tabular}

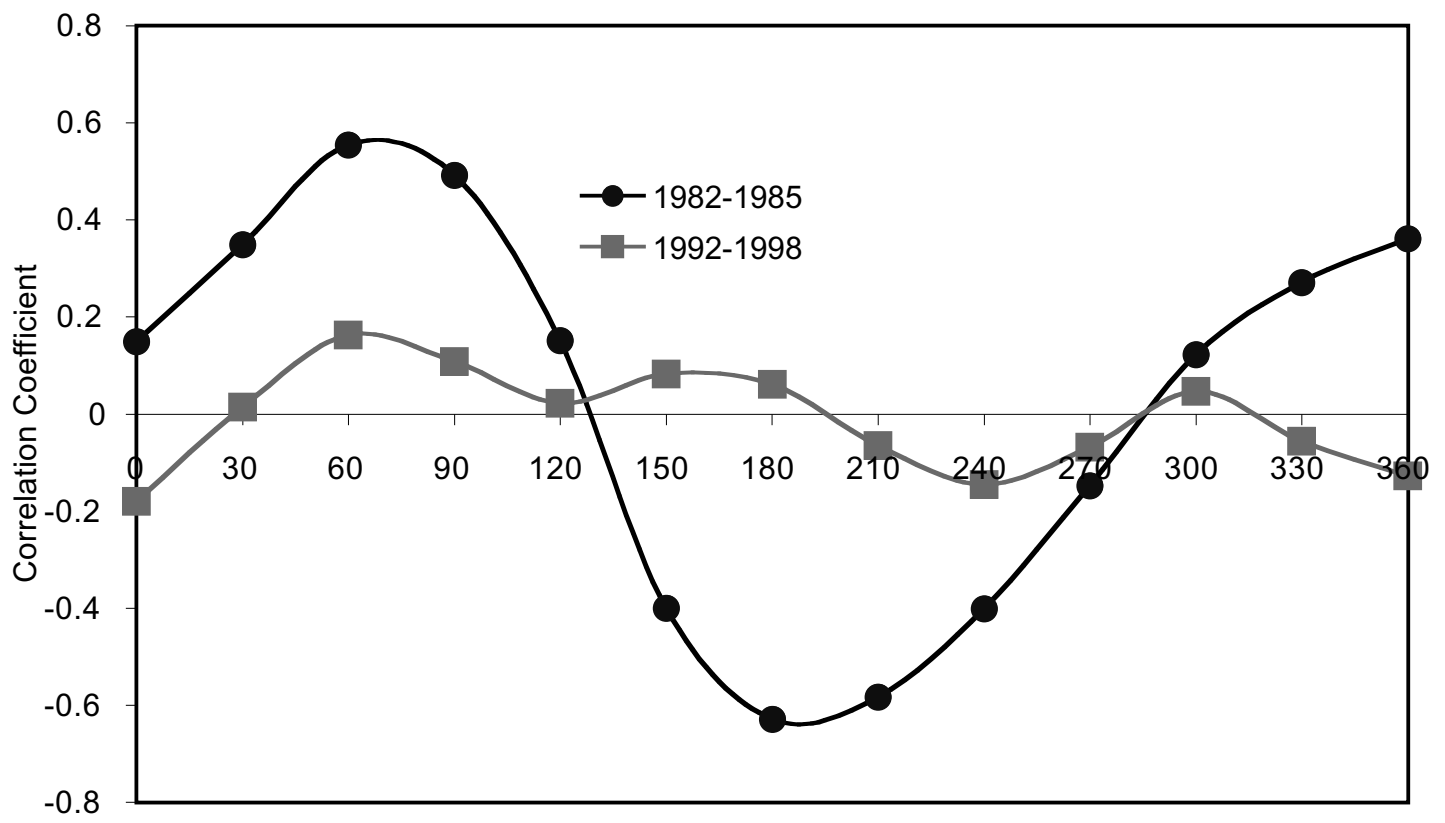

Lag Time (Days)

Fig. 5. Correlation coefficients between the fluctuation of the reservoir's water level and the number of earthquakes per month versus time lag between two series. The maximum coefficient (0.55) occurs at a 60 days time lag for dataset (1982-1985, whole area and depth). The result for another dataset (1992-1998, whole area and depth) is also shown for comparison.

levels by a simple function. It is widely accepted that loading (or unloading) of water and/or increases in pore pressure play important roles in RIS. To simulate this hypothesis, data for daily reservoir's water levels at the dam site are adopted to compose function $\operatorname{FRL}(t)$.

Let's consider two kinds of functions as $\operatorname{FRL}(t)$. In model I, focusing our interests on seasonal variations of RIS, long term changes in reservoir's water levels are reduced via the use of a sort of the high pass filter.

$$
\operatorname{FRL}\left(t_{j}\right)=L_{\mathrm{obs}}\left(t_{j}\right)-\sum_{i=0}^{364} L_{\mathrm{obs}}\left(t_{j-i}\right) / 365 .
$$

In model II, the first derivative of the water level with respect to time is adopted as the reservoir function.

$$
\operatorname{FRL}\left(t_{j}\right)=\left(L_{\mathrm{obs}}\left(t_{j+1}\right)-L_{\mathrm{obs}}\left(t_{j-1}\right)\right) / 2 .
$$

Where, $L_{\text {obs }}\left(t_{j}\right)$ refers to the observed water level on the $j$-th day. The reservoir level function, thus obtained, is directly connected to $\lambda_{r}(t)$ in the form of,

$$
\lambda_{r}(t)=w^{*} \operatorname{FRL}(t-\Delta) .
$$

Where, taking the effect of water diffusion into consideration, $\Delta$ concerns a time delay in the range 0 to 360 days. Parameter $w$ relates the effect of loading and unloading to the intensity. The above intensity sometimes assumes negative 
Table 2. Estimates of DAIC for point-process modeling.

\begin{tabular}{|c|c|c|c|c|c|c|c|c|}
\hline \multicolumn{9}{|c|}{$\begin{array}{c}\text { Model I: } \operatorname{FRL}(t)=(\text { water level }- \text { annual mean of the level }) \\
\text { Model II: } \operatorname{FRL}(t)=(\text { first derivative of the water level })\end{array}$} \\
\hline \multirow{3}{*}{$\begin{array}{l}\text { Depth, } \\
\mathrm{km}\end{array}$} & \multirow{3}{*}{ Lat. } & \multirow{3}{*}{ Long. } & \multirow{3}{*}{$\begin{array}{l}\text { No. of } \\
\text { events }\end{array}$} & \multirow{3}{*}{$\begin{array}{l}\text { ETAS } \\
\text { DAIC }\end{array}$} & \multicolumn{4}{|c|}{ ETAS + Dam } \\
\hline & & & & & \multicolumn{2}{|c|}{ Model I } & \multicolumn{2}{|c|}{ Model II } \\
\hline & & & & & DAIC & Delay & DAIC & Delay \\
\hline $0-40$ & $23.3-24.0$ & $32.3-33.2$ & 238 & 60.21 & 63.48 & 90 & 63.29 & 180 \\
\hline $0-15$ & $23.3-24.0$ & $32.3-33.2$ & 195 & 63.60 & 65.76 & 90 & 66.12 & 180 \\
\hline $15-40$ & $23.3-24.0$ & $32.3-33.2$ & 43 & 3.70 & 8.01 & 90 & 7.15 & 300 \\
\hline $0-40$ & $23.3-24.0$ & $32.3-32.6$ & 77 & 6.09 & 7.61 & 90 & 7.28 & 150 \\
\hline $0-40$ & $23.3-24.0$ & $32.6-33.2$ & 161 & 75.12 & 78.26 & 90 & 78.08 & 180 \\
\hline
\end{tabular}

values and it is not appropriate for use in isolation. However, used with the constant term, $\lambda_{o}$, it becomes possible to satisfy the condition of $\lambda$ being positive.

Aftershock activities were modeled by the epidemic type aftershock sequence (ETAS; Ogata, 1988). The intensity of this component is represented as the sum of contributions from each of the preceding events. The contribution of each event is assumed to have a form:

$$
\lambda_{a i}=K e^{\alpha\left(M_{i}-M_{o}\right)}\left(t+C-t_{i}\right)^{-p}
$$

where $M_{o}$ is threshold magnitude, $K, C, \alpha$, and $p$ are parameters and $M_{i}$ and $t_{i}$ are the magnitude and time of the earlier event $i$. The total intensity at time $t$ is given by the sum of the above three terms,

$$
\lambda(t)=\lambda_{o}+w \operatorname{FRL}(t)+K \sum_{i: t_{i}<t} e^{\alpha\left(M_{i}-M_{o}\right)}\left(t+C-t_{i}\right)^{-p} .
$$

The likelihood function for the point-process with the intensity function $\lambda$ takes the form of,

$$
L\left(t_{1}, t_{2},,, t_{n} ; \theta\right)=\exp \left\{-\int \lambda d t\right\} \prod_{i=1}^{n} \lambda\left(t_{i}\right) .
$$

Here, $t_{1}, t_{2},,, t_{n}$ are the times of earthquake occurrences, and $\theta$ represents model parameters. As additional cases of this model, the models with $w=0$ was also studied. The model parameters except for $\Delta$ were evaluated by the maximum likelihood method. To estimate the parameter of delay term $\Delta$, a grid search method was applied, shifting the value from 0 to 360 days at 30 days interval.

The estimation and comparison among the $\operatorname{FRL}(t)$ were carried out by the method using Davidon's Algorithm for Log Likelihood Maximization (DALL) (Ishiguro and Akaike, 1989). It is natural to have a measure to see which model will most frequently reproduce similar features to those of the given data set. The Akaike Information Criterion (AIC) (Sakamoto et al., 1986),

$$
\begin{aligned}
\mathrm{AIC}= & (-2) \times(\text { max } \log \text { likelihood }) \\
& +2 \times(\text { number of parameters })
\end{aligned}
$$

is useful for such purposes, where the maximum is attained with respect to the parameters. A model with a smaller
AIC is considered to be a better fit to the data. Calculating AIC for a stationary Poisson process, we compare DAIC defined by the difference in AICs between each model and a stationary Poisson process. Therefore, a model with a larger value of DAIC is considered to be better. From the relation between AIC and the entropy, if the difference of AICs between models is larger than 1 or 2 , then the difference is considered to be significant.

The earthquakes from 1992 to 1998 with $m \geq 2.0$ are used for this analysis to avoid the effect of the aftershocks of the 1981 event. Although this time period is shorter than that in the previous analysis by the cross-correlation method, we can analyze data during the seismically stationary period. Taking the effect of earthquake swarms into consideration, we can evaluate the reservoir-induced seismicity. DAIC are calculated for data sets of different depths $(0-15 \mathrm{~km}$, $15-40 \mathrm{~km}$, and $0-40 \mathrm{~km}$ ) and locations (long. $32.3^{\circ}-32.6^{\circ}$, $32.6^{\circ}-33.2^{\circ}$, and $32.3^{\circ}-33.2^{\circ}$ ). Figure 4 shows numbers of monthly events and FRL for model I with depth range (0-40 $\mathrm{km}$ ) and location (long. $32.3^{\circ}-33.2^{\circ}$ ) as an example. The results obtained from this analysis are shown in Table 2 and imply following four conclusions: Firstly, the fact that the smallest DAIC is still larger than 7 indicates that all the models here are better than the stationary Poisson model Secondly, since DAIC for ETAS are 1.5 to 4.3 smaller than those for ETAS plus the reservoir function, we can conclude that the latter is a better statistical model than the former and that the part of the seismicity was caused by the fluctuation of the water level. Thirdly, The best time lag is 90 and about 180 days for Model I and II, respectively. Fourthly, the difference between the maximum DAIC values for the two $\operatorname{FRL}(t)$ models for each same data set is very small and always less than 0.9. Therefore, we cannot conclude which is the better model.

\section{Discussion and Conclusions}

One can distinguish two intervals for the seismicity in and around Lake Nasser (Fig. 3). The first one begins in 1982, enduring to the end of 1986. The second is from the end of 1986 to 1998 . There is a clear difference in the daily numbers of earthquakes between these two segments, which define a higher rate of the seismic activity during the first interval. A correlation coefficient of +0.55 could be obtained for this period at a 60 days time lag. For 1992-1998 
in the second interval, the correlation coefficient is found to be +0.16 at the same time lag. The cross-correlation method gives an idea that there is a strong relationship between the water level and the seismicity for the period (1982-1985) and it is weaker for the period (1992-1998).

The clustering of earthquakes may affect the analysis of the cross correlation so strongly that the hazard function included the ETAS term in our analysis assuming that the clustering can be represented by the epidemic type aftershock sequence. To prevent the effect of a rapid decrease of a number of earthquakes after the 1981 earthquake, we analyze the data with the point-process method during the period of 1992-1998 when the seismic activity became stable. Accordingly, we could assume the background seismicity as the stationary Poisson process. If we use the modified Omori formula instead of the stationary Poisson process as the term of the background seismicity, it will be possible to include data just after the 1981 event in the point-process analysis. However, the estimation error for the background seismicity would affect the estimation of the term of the induced seismicity inaccurately in this case. Therefore, we analyzed only the data of the second term.

The time lags obtained by both the cross-correlation and the point-process analyses are consistent each other. The seismicity became most active about 90 days after the period of the maximum water level (Table 2). This corresponds to the period when the water level changes from highest to lowest stages. This consistency still holds in the result obtained by the cross-correlation method for the period 1992 1998 (Fig. 5), where the correlation coefficients are small and mostly positive for time lags in a range of 0 to 180 days. In the case when we use the hazard function consisted by the first derivative of the water level with respect to time (Model II), we obtained a consistent result with the above. Here, a difference in time lag between Model I and Model II becomes about 90 days and is a reasonable value. For Model I, a lag of 90 days means that the seismicity correlates to the time of the water level decreasing. On the other hand, for Model II, a lag of 180 days corresponds to the minimum of the increasing in the level. Consequently, lags of the both models are consistent with each other.

We found a large coefficient of the cross-correlation analysis during 1982-1985 (Table 1). Since we got the same larger values even if we changed the depth ranges and starting time for analyses, the large value and phase themselves are reliable. However, since some seismic bursts occurred during the period, one may consider that this larger value is apparent not real. Since the aftershock activity of the 1981 earthquake is predominant in this period, we cannot apply the point-process method to this period. Therefore, let's compare results for the cross-correlation analysis for periods of 1982-1985 and 1992-1998 (Table 2 and Fig. 5). Although the correlation coefficient for 1992-1998 is smaller than that for 1982-1985, the delay time with highest correlation coefficients coincides each other. Since the result by the point-process analysis (Table 2) is in good agreement with the result of the cross-correlation analysis, this weak correlation is plausible. Considering consistency of peaks of phases obtained in analyses for the both periods, we can conclude that the phase peak with a high correlation coefficient is not a result of seismic bursts that happened by chance but that the fluctuation of the water level excited the seismicity for a while and as activation of the seismicity results in seismic bursts in this period.

Studying the induced seismicity of the Tarbela reservoir in Pakistan, Ibenbrahim et al. (1989) have reported that correlation coefficients between a number of earthquakes with magnitude less than 2.0 and the water level are 0.86-0.835 for a time lag of 0-300 days and concluded that there is a 160 days lag between the two time-series. Therefore, they concluded that this time lag, equivalent to a 180 phase shift between the water level curve and the event curve, indicates that the frequency of microearthquakes is reduced when the water level is at high stand and vice-versa, and that the positive correlation between the frequency of earthquakes and the low reservoir's water level could be explained mostly by the elastic effects of the reservoir unloading. However, since the water level changes annually, we wonder why correlation coefficients are always positive in their study. According to the recent study using the point-process procedure by Imoto (2001), the seismicity in and around the Tarbela reservoir became active when the water level was decreasing. This result is consistent to our result in Lake Nasser so far as the time lag of the correlation is concerned.

As the mechanism of the reservoir-induced seismicity, the elastic stress change caused by the water weight and the change of the rupture strength caused by the increase of the pore pressure is considered (Simpson et al., 1988). The stress field in the Tarbela reservoir is compressional field with a horizontal $B$ axis. On the other hand, the stress field in the Aswan area is strike-slip type with a vertical $B$ axis (Gaber, 1986). The similarity in the relationship between the water level and seismicity in the different stress regimes may imply that the induced seismicity is not caused by the effect of the water loading but the pore pressure, because the difference between the maximum and minimum stresses does not change in the strike-slip regime.

In summary, we found that the water level of Lake Nasser induced the seismicity in this area with statistical significance. The seismicity became most active about 90 days after the period of the maximum water level. This phase lag implies that the reservoir-induced seismicity here becomes active at the stage when the water level changes from the highest level to the lowest.

Acknowledgments. We'd like to thank Prof. Yomogida for his encouragement as the editor and two anonymous referees for their valuable comments to improve the manuscript.

\section{References}

Anderson, R. E. and R. L. Laney, The influence of late Cenozoic stratigraphy on distribution of impoundment-related seismicity at Lake Mead, Nevada-Arizona, J. Res. U. S. Geol. Surv., 3, 337-343, 1975.

Bell, M. L. and A. Nur, Strength changes due to reservoir-induced pore pressure and stresses and application to Lake Oroville, J. Geophys. Res., 83, 4469-4483, 1978.

Chen, L. Y. and P. Talwani, Reservoir-induced seismicity in China, Pure Appl. Geophys., 153, 133-149, 1998.

Gaber, H. H., Focal mechanisms of earthquakes in Egypt, Bull. Individual Study, Intern. Inst. Seism. Earthq. Engin., Japan, 22, 17-32, 1986.

Gough, D. I. and W. I. Gough, Time dependence and trigger mechanisms for the Kariba (Rhodesia) earthquakes, Eng. Geol., 10, 211-217, 1976.

Gupta, H. K. and B. K. Rastogi, Dams and Earthquakes, Elsevier, Amster- 
dam, pp. 229, 1976.

Ibenbrahim, A., J. Ni, S. Salyards, and I. M. Ali, Induced seismicity of the Tarbela reservoir, Pakistan, Seism. Res. Lett., 60, 185-197, 1989.

Imoto, M., Point process modeling of reservoir induced seismicity, Journal of Applied Probability, 38A, 2001 (in press).

Ishiguro, M. and H. Akaike, DALL, Davidon's Algorithm for log Likelihood Maximization-A FORTRAN Subroutine for Statistical Model Builders-, Computer Science Monograph No. 25, The Institute of Statistical Mathematics, Tokyo, 1989.

Issawi, B., Geology of Nubia west area Western Desert, Egypt, Annals of Geological Survey of Egypt, 8, 237-253, 1978.

Kebeasy, R. M., M. Maamoun, E. Ibrahim, A. Megahed, D. W. Simpson, and W. S. Leith, Earthquake studies at Aswan reservoir, J. Geodynamics, 7, 173-193, 1987.

Kebeasy, R. M., A. I. Bayoumy, and A. A. Gharib, Crustal structure modeling for the northern part of the Aswan Lake area using seismic waves generated by and local earthquakes, J. Geodynamics, 14(1-4), 159-182, 1991.

Keith, C. M., D. W. Simpson, and O. V. Soboleva, Induced seismicity and style of deformation at Nurek reservoir, Tadjik, SSR, J. Geophys. Res., 87, 4609-4624, 1982.

Lee, W. H. K. and J. C. Lahr, HYPO71 (revised): A computer program for determining hypocenter, magnitude, and first motion pattern of local earthquakes, U. S. Geol. Surv., Open File Report, 75-311, 1-116, 1975.

Muco, B., Twenty years seismic monitoring of induced seismicity in northern Albania, Pure Appl. Geophys., 153, 151-162, 1998.
Ogata, Y., Statistical models for earthquake occurrences and residual analysis for point processes, J. Am. Statist. Assoc., 83(401), 9-27, 1988.

Rogers, A. M. and W. H. K. Lee, Seismic study of earthquakes in the Lake Mead, Nevada-Arizona region, Bull. Seism. Soc. Am., 66, 1657-1681, 1976.

Sakamoto, Y., M. Ishiguro, and G. Kitagawa, Akaike Information Criterion Statistics, 290 pp., D. Reidel Publishing Company, 1986.

Sameh, M. M., Seismicity and water level fluctuation in the Aswan High Dam reservoir, Egypt, Bull. Individual Study, Intern. Inst. Seism. Earthq. Engin., Japan, 28, 31-43, 1992.

Simpson, D. W. and S. K. Negmatullaev, Induced seismicity at Nurek reservoir, Tadjikistan, USSR, Bull. Seism. Soc. Am., 71, 1561-1586, 1981.

Simpson, D. W., W. S. Leith, and C. H. Scholz, Two types of reservoirinduced seismicity, Bull. Seism. Soc. Am., 78, 2025-2040, 1988.

Simpson, D. W., A. A. Gharib, and R. M. Kebeasy, Induced seismicity and change in water level at Aswan reservoir, Gerlands Beitrage Zur Geophysik special Issue on Induced Seismicity, 1989.

Snow, D. T., Geodynamics of seismic reservoirs, Proceedings of the Symposium on Percolation through Fissured Rocks, Deut. Ges. ErdGrundbau Stuttgart, T2-J, 1-19, 1972.

M. M. Selim, M. Imoto, and N. Hurukawa (e-mail: hurukawa@kenken. go.jp) 